\title{
Trichloroacetate, an inhibitor of wax biosynthesis, prevents the development of hyperhydricity in Arabidopsis seedlings
}

\author{
Geert-Jan de Klerk ${ }^{1} \cdot$ Dewi Pramanik ${ }^{1,2}$
}

Received: 16 August 2016 / Accepted: 3 July 2017 / Published online: 1 August 2017

(c) The Author(s) 2017. This article is an open access publication

\begin{abstract}
Arabidopsis seedlings developed severe hyperhydricity $(\mathrm{HH})$ when $0.2 \%$ Gelrite was used to solidify the medium instead of $0.7 \%$ agar. One $\mathrm{mM}$ trichloroacetate (TCA, an inhibitor of wax synthesis) strongly reduced the amount of wax. TCA also strongly increased the permeability of leaves for water as shown by a decrease of the water retention capacity. One $\mathrm{mM}$ TCA also fully prevented $\mathrm{HH}$ : the visible symptoms of $\mathrm{HH}$ were absent and the amounts of water and air in the intercellular spaces were as in normal, nonhyperhydric seedlings. Apparently, the excess of water that caused the symptoms of $\mathrm{HH}$ had been removed by the increased cuticular transpiration in the presence of $1 \mathrm{mM}$ TCA.
\end{abstract}

Keywords Cuticula $\cdot$ Hyperhydricity $\cdot$ Intercellular spaces $\cdot$ Cuticular transpiration $\cdot$ Trichloroacetate $\cdot$ Wax

$\begin{array}{ll}\text { Abbreviations } \\ \text { DW } & \text { Dry weight } \\ \text { FW } & \text { Fresh weight } \\ \text { HH } & \text { Hyperhydricity } \\ \text { RH } & \text { Relative humidity } \\ \text { TCA } & \text { Trichloroacetate } \\ \text { WRC } & \text { Water retention capacity }\end{array}$

Communicated by Sergio J Ochatt.

Geert-Jan de Klerk

geertjan.deklerk@wur.nl

1 Plant Breeding, Wageningen UR, PO Box 6700 AA, Wageningen, Netherlands

2 Indonesian Ornamental Crops Research Institute, Jl. Raya Ciherang, Pacet-Cianjur 43253, Indonesia

\section{Introduction}

The physiological disorder HH (hyperhydricity) occurs frequently in tissue culture (Rojas-Martínez et al. 2010) and occasionally under ex vitro conditions (Correll et al. 2000; Du Chatenet et al. 2000). Hyperhydric tissues are characterized by a high water content. Under natural conditions, fluctuations in water content of plant tissues are related to changes in the size of cells (Canny and Huang 2006). In correspondence with this, it was believed that the excess of water in hyperhydric tissues was related to swelling of the cells. The swelling was supposedly caused by reduced wall pressure brought about by a reduction in the levels of cellulose and lignin (George 1996). More recently, though, it has been observed that in hyperhydric tissues the extra water replaces the air in the apoplast (Gribble et al. 1998; Van den Dries et al. 2013). The apoplast consists of the cell wall continuum and the intercellular spaces (for a review on the terminology, see Canny 1995).

Because of the flooding of the apoplast, gas exchange by cells becomes severely inhibited and as a result the cells suffer from anaerobiosis and accumulation of gases like ethylene (Gribble et al. 2003; Van den Dries et al. 2013). The poor gas exchange leads to the symptoms of HH. In Arabidopsis seedlings, severe HH leads to dying off 3 weeks after the first visible symptoms (Van den Dries et al. 2013). Evidently, the excess of water is brought about by too much entering and/or too little removal of water. Thus, methods to reduce HH involve a reduction of water uptake (for example by increasing the concentration of gelling agent, Delarue et al. 1997) or a stimulation of transpiration [by reducing the relative humidity in the headspace of the tissue culture container, Saher et al. (2005)].

It is often maintained that plants in vitro do not transpire as the RH (relative humidity) is believed to be saturated. 
However, the RH under normal tissue culture conditions is only 95-99.5\% (Chen 2004; Saher et al. 2005) and not $100 \%$. The transpiration in vitro is a few percent of the transpiration under ex-vitro conditions (De Klerk 2010). Water transpires from plant tissues via the stomata and via the cuticle. The movement of water through the cuticle is strongly inhibited by a wax layer so that cuticular transpiration is only small. In plants growing ex vitro, stomatal transpiration usually makes up more than $95 \%$ of the total transpiration (Kerstiens 1996).

Waxes are very long chain lipid molecules. There are two layers of cuticular wax: Wax embedded within the cuticle and wax on the outer surface (Buschhaus and Jetter 2011). The former is designated as 'intracuticular wax' and the latter as 'epicuticular wax'. Apart from being a barrier to water loss, these wax layers protect plants from pathogens and ultraviolet radiation. The synthesis of wax is blocked by TCA (trichloroacetate). In developing maize leaves, TCA inhibits the incorporation of ${ }^{14} \mathrm{C}$-acetate in $\mathrm{C}_{32}$ chains (Dewey et al. 1962). TCA reduces wax in both layers but at different rates.

A reduction of the wax layer enhances transpiration of water by the leaves, but the thickness of the cuticle is not exactly related to its effectiveness as barrier (Kerstiens 2006). In the present paper, we examine whether the symptoms of $\mathrm{HH}$ are reduced by stimulating transpiration through inhibiting wax synthesis and whether apoplastic air and water volumes show the relative amounts characteristic for nonhyperhydric plants as reported by Van den Dries et al. (2013).

\section{Materials and methods}

\section{Plant material and tissue culture conditions}

Arabidopsis thaliana (Col-0) seeds were sterilized with $70 \%$ (v/v) ethanol for $1 \mathrm{~min}, 2 \%$ (w/v) sodium hypochlorite for $15 \mathrm{~min}$ and subsequently rinsed three times for 10 min with sterilized distilled water. Sterile seeds were transferred to Petri dishes with half-strength MS basal salt mixture including vitamins (Murashige and Skoog 1962) supplemented with $1.5 \%(\mathrm{w} / \mathrm{v})$ sucrose and solidified with $0.7 \%(\mathrm{w} / \mathrm{v}$ ) Microagar (all from Duchefa Biochemie, Haarlem, The Netherlands). Seeds were stratified in the dark for 3 days at $4{ }^{\circ} \mathrm{C}$ and after that germinated in a growth chamber with $16 \mathrm{~h} \mathrm{light} / 8 \mathrm{~h}$ dark $\left(30 \mu \mathrm{mol} \mathrm{m} \mathrm{m}^{-2} \mathrm{~s}^{-1}\right.$, Philips TL33) at $21^{\circ} \mathrm{C}$. To induce $\mathrm{HH}, 7$-days-old seedlings were transferred to high Petri dishes (nine seedlings per dish) containing the same nutrient medium solidified with $0.2 \%$ (w/v) Gelrite (Duchefa Biochemie). Control seedlings were transferred to fresh nutrient medium solidified with $0.7 \%$ (w/v) Microagar. To both media, TCA was added as indicated. Per condition, three dishes were prepared. The dishes were sealed with two layers of household foil. Photographs were made 14 days after transfer. At 14 days, all leaves (ca. 10 leaves per seedling) were evaluated under the binocular with respect to $\mathrm{HH}$; curled edges of the leaves and a dark green colour were used as criteria (Fig. 1). For each dish, the percentage of hyperhydric leaves was calculated and for each condition the mean of these percentages.

\section{Estimation of the volumes of apoplastic water and air}

Fourteen days after the transfer, apoplastic water was extracted from leaf tissues by mild centrifugation according to Terry and Bonner (1980). Leaves were excised from plants, weighed and placed into a spin mini filter microcentrifuge tube (Starlab, Ahrensburg, Germany). Leaves were centrifuged at $3000 \times g$ for $20 \mathrm{~min}$ at $4{ }^{\circ} \mathrm{C}$. Immediately after centrifugation, the leaves were reweighed. The presence of symplastic contamination in the apoplastic water was previously assessed by a malate dehydrogenase assay and found to be negligible (Van den Dries et al. 2013). The apoplastic water volume $\left(\mathrm{V}_{\text {water }}\right)$ in $\mu \mathrm{lg}^{-1} \mathrm{FW}$ was calculated using the formula: $V_{\text {water }}=\frac{F W-W_{a c}}{F W}$, where $\mathrm{FW}=$ fresh weight (mg) of leaves and $\mathrm{W}_{\mathrm{ac}}=$ weight (mg) of leaves after centrifugation. The difference in weight in the numerator is the amount of water (in mg) that had been removed by centrifugation. This amount was re-appraised as a volume taking the water density as $1 \mathrm{mg} \mathrm{Il}^{-1}$.

The volume of apoplastic air in leaves was estimated using a pycnometer with stopper (Raskin 1983). Leaves were excised, weighed and placed into the pycnometer. The
Fig. 1 Normal (left) and hyperhydric (right) leaves of Arabidopsis. The normal ones had grown for 10 days on medium solidified with $0.7 \%$ agar and the hyperhydric ones for 10 days on medium solidified with $0.2 \%$ Gelrite
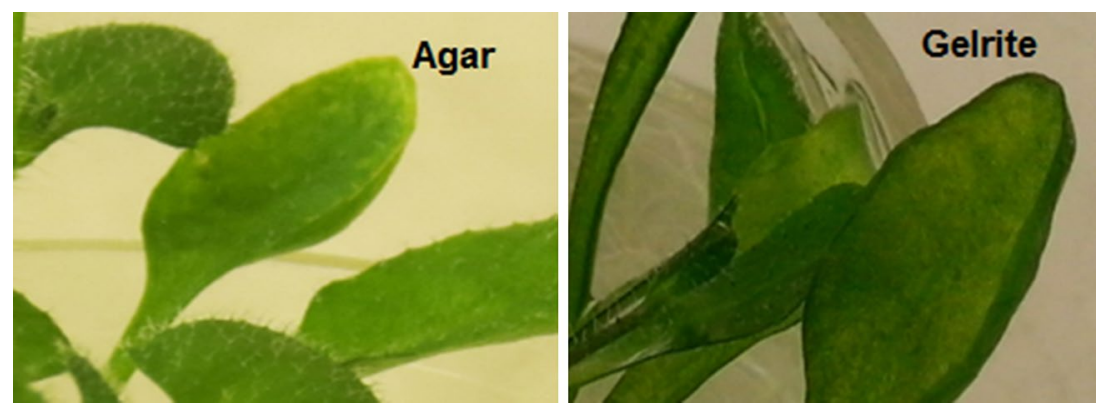
pycnometer was filled with distilled water and stoppered. Water on the exterior of the pycnometer was carefully removed with filter paper. The weight of the full pycnometer (including water and leaves) was determined and the pycnometer with water and leaves was subjected to vacuum $(500 \mathrm{~mm} \mathrm{Hg}$ ) for $5 \mathrm{~min}$ to remove air from the leaves and replace it by water. When required, the vacuum treatment was repeated until all air had been removed from the apoplast and the leaves had sunk to the bottom of the pycnometer (Fig. 2). The leaves did sink to the bottom when air had been replaced by water because the specific gravity of the non-gaseous fraction in leaves is in the range 1-1.3 (Roderick et al. 1999). After vacuum infiltration, the pycnometer was refilled, dried and reweighed. The apoplastic air volume $\left(\mathrm{V}_{\text {air }}\right)$ in $\mu \mathrm{g} \mathrm{g}^{-1} \mathrm{FW}$ was calculated using the following formula $\mathrm{V}_{\mathrm{air}}=\frac{\mathrm{W}_{\mathrm{av}}-\mathrm{W}_{\mathrm{bv}}}{\mathrm{FW}}$, where $\mathrm{W}_{\mathrm{bv}}=$ weight (mg) of the pycnometer including leaves and water before vacuum infiltration, $\mathrm{W}_{\mathrm{av}}=$ weight $(\mathrm{mg})$ of the pycnometer including leaves and water after vacuum infiltration and $\mathrm{FW}=$ fresh weight $(\mathrm{g})$ of leaves; the water density was taken as $1 \mathrm{mg} \mu \mathrm{l}^{-1}$. Care was taken that the temperature of the water remained constant.

The apoplastic water and air determinations were done with 4 and 3 samples respectively per condition. Each sample consisted of two shoots.
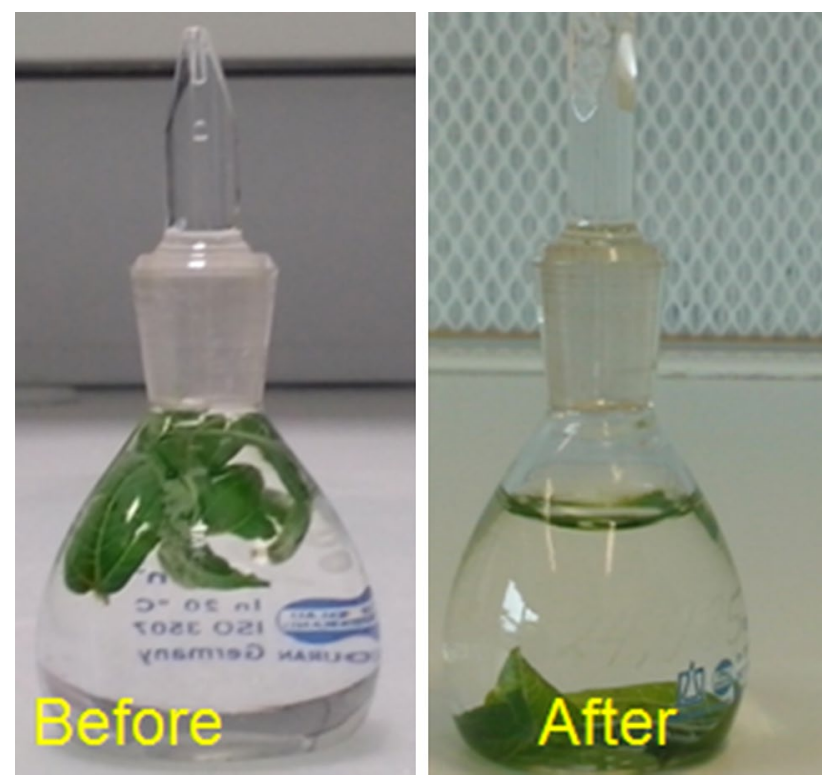

Fig. 2 Leaves of Arabidopsis in a pycnometer before the vaccuum treatment (left) and after (right). The leaves were from seedlings growing on agar. Note that the leaves float on the surface of the water in the left picture, but have sunk to the bottom at the right photo. The leaves shown right have also turned darkgreen caused by filling the intercellular spaces by water. (Color figure online)

\section{Determination of cuticular wax}

Cuticular wax was measured gravimetrically according Silva Fernandes et al. (1964). Leaves of 8 shoots were immersed, one shoot at a time, in $30 \mathrm{ml}$ redistilled chloroform for $30 \mathrm{~s}$. The chloroform was allowed to evaporate for $24 \mathrm{~h}$ in an active hood and the residue was weighed. The amount of wax was calculated per $\mathrm{cm}^{2}$ leaf surface. The leaf surface was determined using Image J4.40 (http:// rsbweb.nih.gov/ij/, 2013). Chloroform releases both intraand epicuticular waxes, so the overall wax content was assessed (Walton 1990). For each condition, three samples of eight shoots were taken.

\section{Measurement of WRC (water retention capacity)}

The WRC of detached leaves was measured 14 days after transfer of seedlings to Gelrite or agar media according to De Klerk and Wijnhoven (2005) with minor modifications. Leaves excised from three seedlings and FW (fresh weight, $\mathrm{mg}$ ) was measured $\left(\mathrm{FW}_{\text {start }}\right)$. Leaves were then allowed to evaporate water at $22^{\circ} \mathrm{C}$ and $48 \%$ relative humidity and were weighed $(\mathrm{mg})$ after 30, 60120 and $240 \mathrm{~min}\left(\mathrm{FW}_{\mathrm{t}}\right)$. DW (Dry weight, $\mathrm{mg}$ ) was determined after keeping the leaves overnight in an oven at $70^{\circ} \mathrm{C}$. The water retention (WR) as a percentage of the total water at the start was calculated according to the formula: $\mathrm{WR}_{\mathrm{t}}=100-100 \times \frac{\left(\mathrm{FW}_{\text {start }}-\mathrm{FW}_{\mathrm{t}}\right)}{\left(\mathrm{FW}_{\text {start }}-\mathrm{DW}\right)}$. For each treatment, the time required to achieve $50 \%$ water loss was estimated by extrapolation using the curves of the individual shoots. Each value is the mean of 3 determinations.

\section{Statistics}

For each parameter, the mean $\pm \mathrm{SE}$ was determined. The number of biological replicates is indicated in the description of the method. Significant differences from the control were determined with the Student's $t$-test and the levels of significance are shown in the graphs $\left({ }^{*} P<0.05\right.$; $* * P<0.01 ; * * * P<0.0001)$.

\section{Results}

\section{TCA prevents the development of HH}

In many crops, shoots cultured on medium solidified with Gelrite develop HH whereas shoots with agar as gelling agent show little or no symptoms of HH (De Klerk et al. 2017). Accordingly, almost all Arabidopsis seedlings cultured on Gelrite developed severe HH (Fig. 3b), but no 

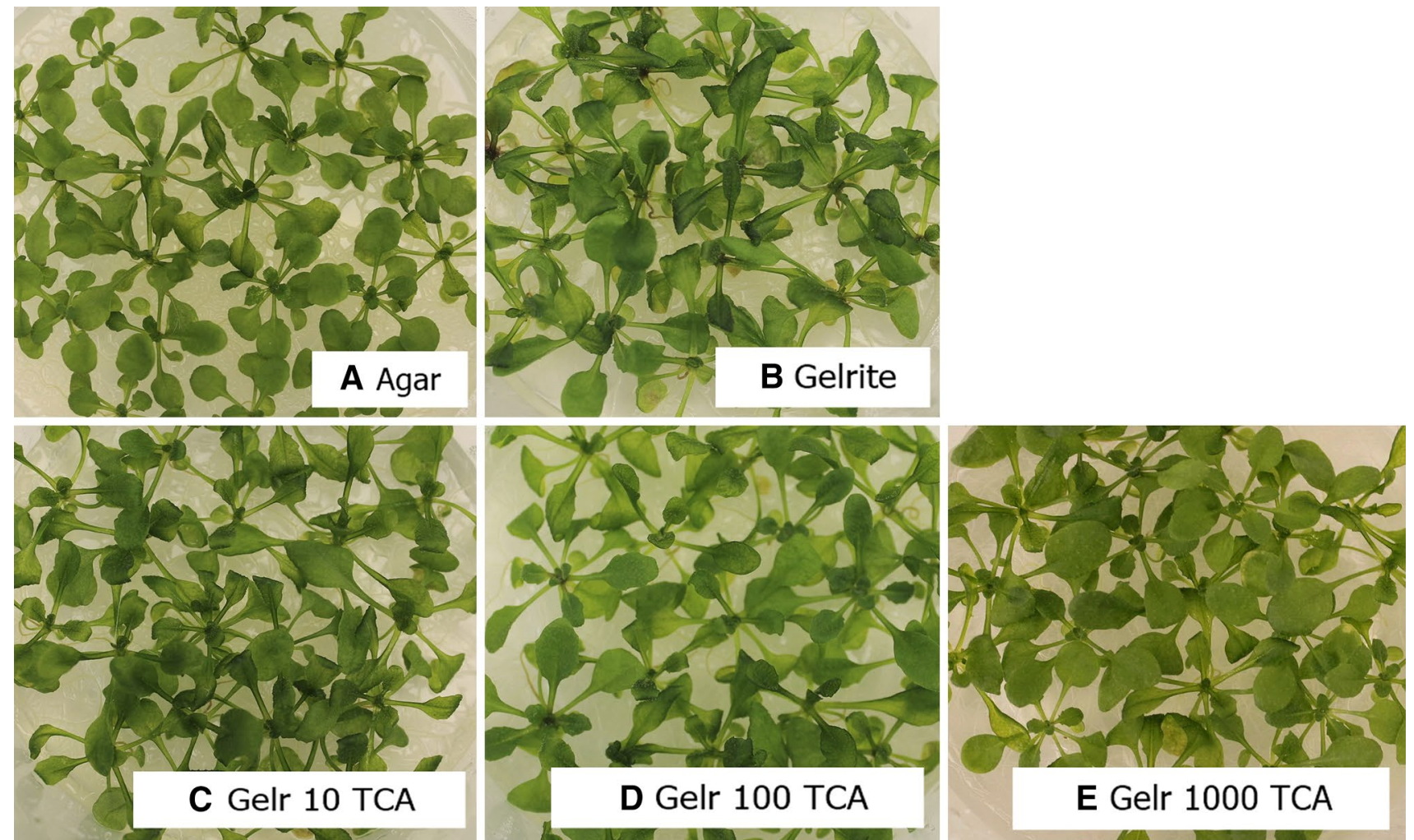

Fig. $3 \mathrm{HH}$ in Arabidopsis seedlings treated with TCA. Seedlings were cultured for 7 days on $0.7 \%$ agar, and then transferred to fresh medium with $0.7 \%$ agar or to $0.2 \%$ Gelrite with $0,10,100$ or $1000 \mu \mathrm{M}$ TCA. Photographs were taken 14 days after transfer of the seedlings. a Seedlings cultured on $0.7 \%$ agar exhibited no symptoms of HH. b Seedlings cultured on $0.2 \%$ Gelrite developed HH. c, $\mathbf{d}$ and e When TCA $(10,100$ or $1000 \mu \mathrm{M}$ respectively) was added to the Gelrite medium, the development of $\mathrm{HH}$ was reduced or prevented

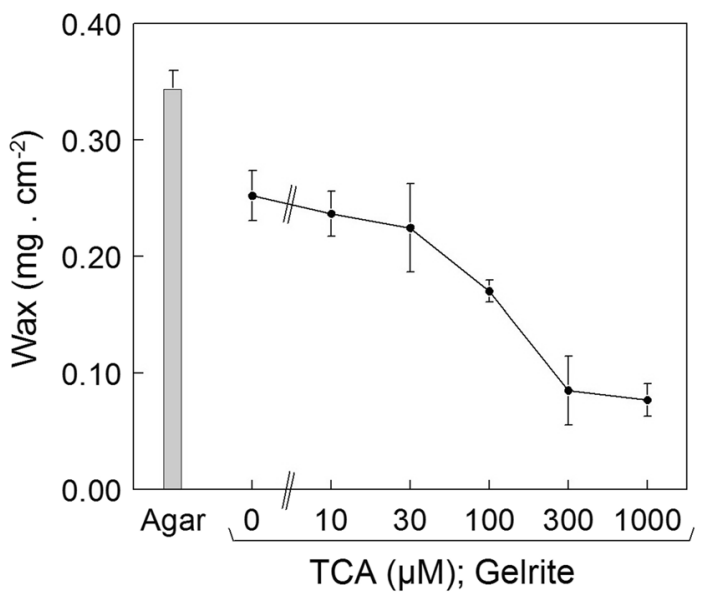

Fig. 4 Amount of wax extracted by rinsing leaves for $30 \mathrm{~s}$ in chloroform. The leaves were from seedlings that had grown after transfer for 14 days at $0.7 \%$ agar or $0.2 \%$ Gelrite with increasing concentrations of TCA 


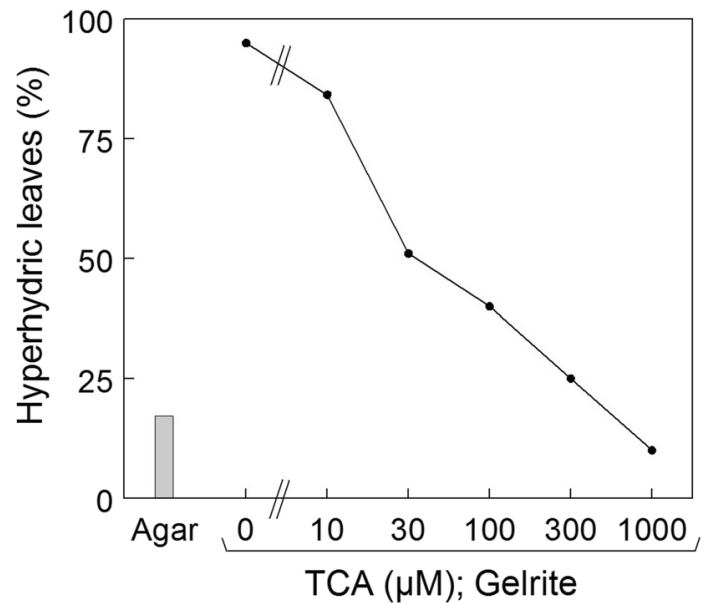

Fig. 5 The percentage of leaves displaying HH symptoms 14 days after transfer to medium with $0.7 \%$ agar or to $0.2 \%$ Gelrite with increasing concentrations of TCA

\section{Water status}

Previously, we noted a large volume of air in the apoplast of agar-grown seedlings ( $80 \%$ of the volume of the apoplast) (Van den Dries et al. 2013). In the present research, this percentage was a little higher (90\%). In hyperhydric Gelrite-grown plants, the apoplast was almost completely filled with fluid $(70 \%)$. TCA reduced the amount of water in the apoplast and increased the amount of air (Fig. 6). The amount of apoplastic water in 1000- $\mu$ M-TCA Gelritecultured plantlets was even lower than in agar-cultured plantlets $(P<0.05)$.

We examined whether the decrease of wax did lead to an increased permeability of the cuticle for water. To this end, we determined water retention capacity (WRC) of detached leaves after transfer from the very high RH in vitro (95-99.5\%, Chen 2004; Saher et al. 2005) to ambient RH (48\%). If TCA influences the permeability for water, the WRC of TCA treated seedlings would be reduced. During the initial $30 \mathrm{~min}$ of exposure to ambient
$\mathrm{RH}$, the control seedlings ( $0 \mu \mathrm{M}$ TCA) lost $35 \%$ of the water present in leaves, whereas $1000-\mu \mathrm{M}$-TCA grown seedlings lost 58\%, so the loss was $65 \%$ higher (Fig. 7). In the control, the time point at which $50 \%$ water loss had been reached was $53 \mathrm{~min}$, with $1000 \mu \mathrm{M}$ this had decreased to $28 \mathrm{~min}$. These data show that TCA strongly reduced WRC.

\section{Discussion}

The term HH indicates that plantlets that suffer from this disorder contain too much water. Accordingly, the dry weight percentage (DW\%) of hyperhydric plants is lower than the DW\% of unaffected plants although not much (Rojas-Martínez et al. 2010). The underlying cause of $\mathrm{HH}$ has only occasionally been examined. Most articles

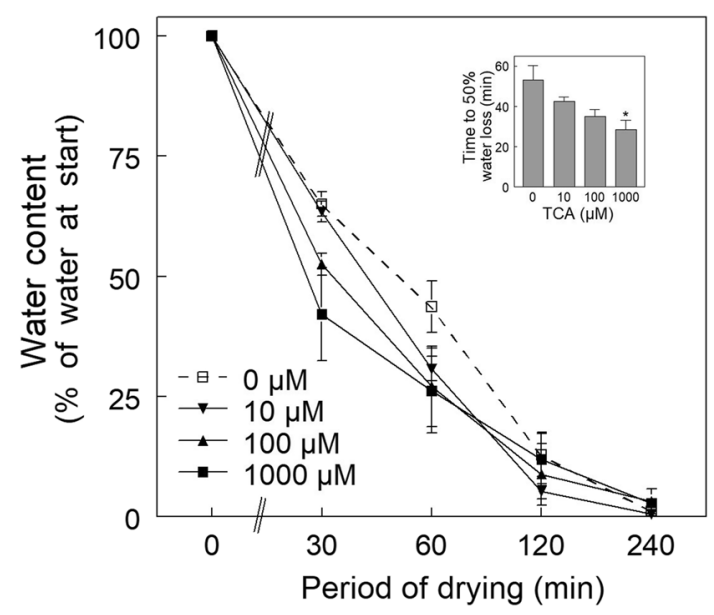

Fig. 7 Water content of detached eaves exposed to ambient atmosphere $(48 \% \mathrm{RH})$. The leaves were from seedlings that had grown after transfer for 14 days at $0.7 \%$ agar or $0.2 \%$ Gelrite with increasing concentrations of TCA. The inset shows the time at which $50 \%$ water loss had been reached as determined by extrapolation
Fig. 6 Amounts of water (a) and air (b) in the apoplast of leaves of seedlings 14 days after transfer to $0.7 \%$ agar or $0.2 \%$ Gelrite with increasing TCA concentration. Each value is the mean of four samples of nine seedlings $\pm \mathrm{SE}$
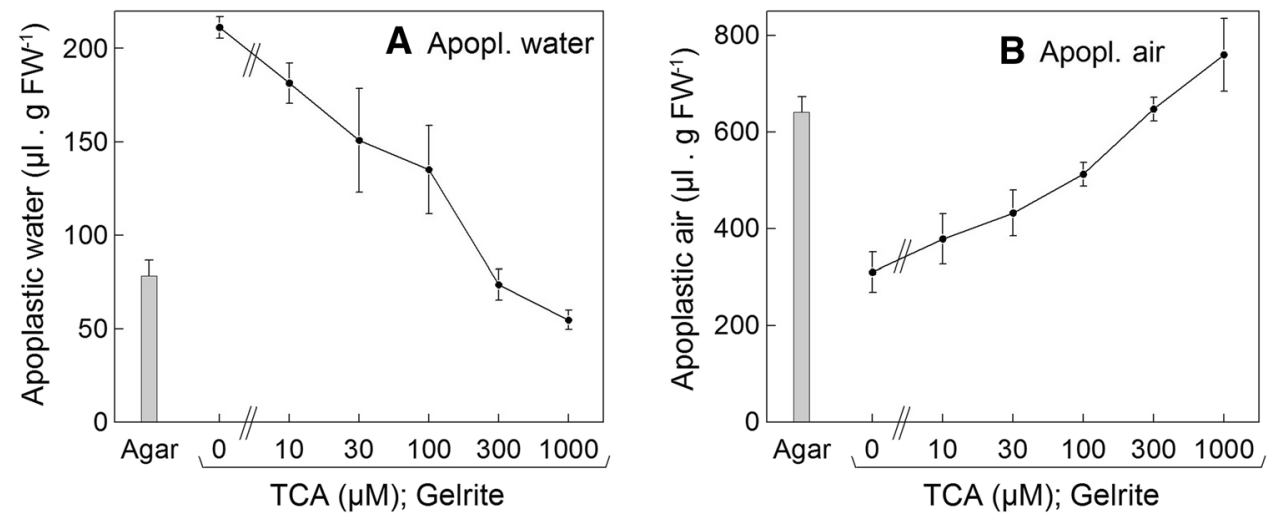
on $\mathrm{HH}$ deal with tissue culture conditions that reduce the disorder or with the symptoms on the anatomical, biochemical and, occasionally, molecular levels.

With respect to the cause(s) of $\mathrm{HH}$, it should be noted first of all that the high water content of the tissue is the most essential feature since conditions that reduce uptake of water (e.g., a high concentration of gelling agent, Delarue et al. 1997) or increase the removal of water from the plant tissue (a reduction of the RH in the headspace, Saher et al. 2005) prevent the development of HH. Why is the excess of water harmful and sometimes even lethal? The detrimental effect is attributable to the localization of the extra water in the apoplast. Gribble et al. (2003) and Van den Dries et al. (2013) discuss the effects of the abundance of water instead of air in the apoplast. The main consequence is a distortion of gas exchange because the diffusion of gases in water is 10,000 times slower than in air (Jackson 1985). The inability to exchange gases is demonstrated by the occurrence of anaerobiosis in hyperhydric plants (Van den Dries et al. 2013). Internal translocation of gases is essential for vascular plants. This concerns not only $\mathrm{O}_{2}$ and $\mathrm{CO}_{2}$ but also, e.g., gaseous hormones like methyl jasmonate and ethylene.

Next, the reason(s) why the apoplast is flooded should be considered together with possible treatments. As noted before, abundant entering and/or poor removal of water are central to the development of $\mathrm{HH}$. The former is related to the type and concentration of the solidifying agent and, possibly, to the hydrophilicity of the walls of the xylem and the intercellular spaces (Raven 1996). The poor removal is brought about by the very high RH in the headspace and by a low permeability of the epidermis with respect to water due to properties of the stomata and the wax layer. The present paper deals with the effect of a large increase of the permeability of the epidermis by adding TCA.

Dewey et al. (1956) reported that spraying plants of Pisum sativum L. and Brassica with TCA inhibits wax deposition. TCA decimates the incorporation of ${ }^{14} \mathrm{C}$-acetate in wax blocking the elongation between $\mathrm{C}_{28}$ and $\mathrm{C}_{30}$ and also between $\mathrm{C}_{30}$ and $\mathrm{C}_{32}$ (Mikkelsen 1978). TCA is being used as an herbicide: The TCA-treatment increases transpiration and thereby causes wilting. When in our experiments Arabidopsis seedlings were treated with $1 \mathrm{mM}$ TCA, a $70 \%$ reduction of wax observed (Fig. 4).

As noted before, plants in tissue culture also transpire water. As TCA increases the permeability (Fig. 7), this transpiration will increase, preventing the flooding of the protoplast and thereby the development of $\mathrm{HH}$. At the highest concentration tested $(1000 \mu \mathrm{M})$, HH had disappeared as judged by visual inspection (Figs. 3, 5) and by the amounts of water and air in the apoplast (Fig. 6). The most likely explanation is that the poor wax layer deposited in the presence of TCA is relatively permeable for water. It can, however, not be excluded that TCA acts by having a positive effect on the stomata that are often in a poor condition in hyperhydric plants (e.g., Van den Dries et al. 2013; Yu et al. 2011). Remarkably, as judged by their visual appearance, the seedlings do no show negative side-effects at the highest TCA concentration tested. Finally, it should be noted that the causal relationship between closure of the stomata and flooding of the apoplast is not as straightforward as it seems since flooding of the apoplast brings about closure of the stomata (Sibbernsen and Mott 2010). In other words, the closure of the stomata may be both the cause and the effect of $\mathrm{HH}$.

Plants without a wax layer will not survive after transplanting. The absence of a wax layer is unlikely a problem in commercial micropropagation as plants can be allowed to recover before exflasking during an additional subculture cycle and/or an in-vitro rooting step. It has been reported that there is no carry-over of the TCA effect after a pulse treatment. However, wilting caused by the absence of wax may also occur in vitro during propagation in spite of the very high RH: we added TCA to shoot cultures of apple and they fully wilted in vitro (Klerk and Pramanik, unpubl. results). Apparently shoot cultures (that have no roots; Arabidopsis seedlings do have roots) were not able to take up sufficient water from the solidified medium to replace water lost by the additional transpiration caused by TCA. When a layer of liquid medium was added on top of the solidified medium, the induction of wilting by TCA was fully absent. These results indicate that practical use of TCA to prevent $\mathrm{HH}$ still requires extensive research.

Another potential application of TCA in tissue culture is easing of the uptake of medium components. Particularly in liquid medium, medium components may enter the explants all over the surface of the TCA-treated shoots. Under normal tissue culture conditions uptake is problematic for three reasons. (1) Under normal conditions, uptake is largely restricted to the cut surface due to the impermeability of the cuticle (Guan and De Klerk 2000). (2) Moreover, within a few days after preparing the explant, uptake via the cut surface is strongly reduced by wound repair (Smulders et al. 1990; Wilms et al. 1990). (3) Finally when uptake occurs via the cut surface, the compounds have to be transported within the explant to the areas where growth occurs. About this transport nothing is known but it may well be problematic in many species (De Klerk 2010).

Acknowledgements This work was supported by the Technological. Top Institute Green Genetics (TTI GG). DP received a fellowship from the Indonesian Agency for Agricultural. Research and Development.

Author contributions GD and DP conceived and designed the research, DP conducted the experiments and GD wrote the manuscript. Both authors read and approved the manuscript. 


\section{Compliance with ethical standards}

Conflict of interest All authors declare that they have no conflict of interest.

Open Access This article is distributed under the terms of the Creative Commons Attribution 4.0 International License (http:// creativecommons.org/licenses/by/4.0/), which permits unrestricted use, distribution, and reproduction in any medium, provided you give appropriate credit to the original author(s) and the source, provide a link to the Creative Commons license, and indicate if changes were made.

\section{References}

Buschhaus C, Jetter R (2011) Composition differences between epicuticular and intracuticular wax substructures: How do plants seal. their epidermal surfaces? J Exp Bot 62:841-853

Canny MJ (1995) Apoplastic water and solute movement: new rules for an old space. Annu Rev Plant Physiol Mol Biol 46:215-236

Canny MJ, Huang CX (2006) Leaf water content and palisade cell size. New Phytol 170:75-85. doi:10.1111/j.1469-8137.2005.01633.x

Chen C (2004) Humidity in plant tissue culture vessels. Biosyst Eng 88:231-241

Correll MJ, Wu Y, Weathers PJ (2000) Controlling hyperhydration of carnations (Dianthus caryophyllus L.) grown in a mist reactor. Biotechnol Bioeng 71:307-314

De Klerk GJ (2010) Why plants grow in tissue culture. Prophyta Annu 2010:42-44

De Klerk GJ, Wijnhoven F (2005) Water retention capacity of tissuecultured plants: Performance of leaves from in vitro germinated mungbean seedlings. Propag Ornam Plants 5:14-18

De Klerk GJ, Van Den Dries N, Krens F (2017) Hyperhydricity: underlying mechanisms. Acta Hortic 1155:269-276

Delarue M, Santoni V, Caboche M, Bellini C (1997) Cristal mutations in Arabidopsis confer a genetically heritable, recessive, hyperhydric phenotype. Planta 202:51-61

Dewey OR, Gregory P, Pfeiffer RK (1956) Factors affecting the susceptibility of peas to selective dinitro herbicides. Proc $3 \mathrm{rd} \mathrm{Br}$ Weed Contr Conf 1:313-326

Dewey OR, Hartley GS, MacLauchlan JWG (1962) External. leaf waxes and their modification by root-treatment of plants with trichloroacetate. Proc Royal Soc London Series B 155:532-550

Du Chatenet C, Latché A, Olmos E, Ranty B, Charpenteau M, Ranjeva R, Pech JC, Graziana A (2000) Spatial-resolved analysis of histological. and biochemical. alterations induced by water-soaking in melon fruit. Physiol Plant 110:248-255

George EF (1996) Plant propagation by tissue culture. Part 2. In practice. Exegetics Limited, Edington

Gribble K, Tingle J, Sarafis V, Heaton A, Holford P (1998) Position of water in vitrified plants visualised by NMR imaging. Protoplasma 201:110-114

Gribble K, Sarafis V, Conroy J (2003) Vitrified plants: towards an understanding of their nature. Phytomorphology 53:1-10

Guan H, De Klerk GJ (2000) Stem segments of apple microcuttings take up auxin predominantly via the cut surface and not via the epidermal surface. Sci Hortic 86:23-32
Jackson MB (1985) Ethylene and responses of plants to soil waterlogging and submergence. Annu Rev Plant Physiol Plant Mol Biol $36: 145-174$

Kerstiens G (1996) Cuticular water permeability and its physiological. significance. J Exp Bot 47:1813-1832

Kerstiens G (2006) Water transport in plant cuticles: An update. J Exp Bot 57:2493-2499. doi:10.1093/jxb/erl017

Mikkelsen JD (1978) The effects of inhibitors on the biosynthesis of the long chain lipids with even carbon numbers in barley spike epicuticular wax. Carlsberg Res Commun 43:15-35

Murashige T, Skoog F (1962) A revised medium for rapid growth and bioassays with tobacco tissue cultures. Physiol Plant 15:473-497

Raskin I (1983) A method for measuring leaf volume, density, thickness, and internal gas volume. HortScience 18:698-699

Raven JA (1996) Into the voids: the distribution, function, development and maintenance of gas spaces in plants. Ann Bot 78:137142. doi:10.1006/anbo.1996.0105

Roderick ML, Berry SL, Noble IR, Farquhar GD (1999) A theoretical approach to linking the composition and morphology with the function of leaves. Funct Ecol 13(5):683-695. doi:10.1046/j.1365-2435.1999.00368.x

Rojas-Martínez L, Visser RGF, de Klerk GJ (2010) The hyperhydricity syndrome: waterlogging of plant tissues as a major cause. Propag Ornam Plants 10:169-175

Saher S, Piqueras A, Hellin E, Olmos E (2005) Prevention of hyperhydricity in micropropagated carnation shoots by bottom cooling: implications of oxidative stress. Plant Cell Tissue Organ Cult 81:149-158

Sibbernsen E, Mott KA (2010) Stomatal. responses to flooding of the intercellular air spaces suggest a vapor-phase signal. between the mesophyll and the guard cells. Plant Physiol 153:1435-1442

Silva Fernandes AMS, Baker EA, Martin JT (1964) Studies on the plant cuticle. VI. The isolation and fractionation of cuticular waxes. Ann Appl Biol 53:43-45

Smulders MJM, Visser EJW, Van Der Krieken WM, Croes AF, Wullems GJ (1990) Effects of the developmental. state of the tissue on the competence for flower bud regeneration in pedicel explants of tobacco. Plant Physiol 92:582-586

Terry ME, Bonner BA (1980) An examination of centrifugation as a method of extracting an extracellular solution from peas, and its use for the study of indoleacetic acid-induced growth. Plant Physiol 66:321-325. doi:10.1104/pp.66.2.321

Van den Dries N, Giannì S, Czerednik A, Krens FA, De Klerk GJM (2013) Flooding of the apoplast is the key factor in the development of hyperhydricity. J Exp Bot. doi:10.1093/jxb/ert315

Walton TJ (1990) Waxes, cutin and suberin. In: Harwood JL, Boyer J (eds) Methods plant biochem, vol 4. Academic Press, New York, pp 106-158

Wilms FHA, Neelissen JAM, Kroh M (1990) Suberization and bud formation in tobacco explants. New Phytol 114:563-570

Yu Y, Zhao Y-Q, Zhao B, Ren S, Guo Y-D (2011) Influencing factors and structural characterization of hyperhydricity of in vitro regeneration in Brassica oleracea var. italica. Can J Plant Sci 91:159-165. doi:10.4141/cjps10034 